\title{
A Case Study of Carbon Sequestration Potential of Land Use Policies Favoring Re-growth and Long-term Protection of Temperate Forests
}

\author{
Chad J. McGuire (Corresponding author) \\ Department of Public Policy, University of Massachusetts Dartmouth \\ 285 Old Westport Road, Dartmouth, MA 02747, USA \\ Tel: 1-508-999-8520Ｅ-mail: cmcguire@umassd.edu
}

\begin{abstract}
There is a traditional view suggesting forests remove carbon dioxide from the atmosphere (Pregitzer \& Euskirchen, 2004), but they cease to serve as a carbon sink as they fully mature (Odum, 1969). Recent modeling of old-growth forest carbon sequestration indicate they continue to serve as a "net sink" of carbon even after maturity (Carey, Sala, Keane, \& Callaway, 2001; Zhou et al., 2006) - sequestering an average of $2.4+/-0.8 \mathrm{tC} \mathrm{ha}^{-1} \mathrm{yr}^{-1}$ ( $\mathrm{tC}=$ metric tons of carbon; ha = hectare; $y r=y e a r)$, and yielding a ratio of heterotrophic respiration $(\mathrm{Rh})$ to net primary production (NPP) of approximately $0.65+/-0.02$ (Luyssaert et al., 2008). These figures show the strongest correlation amongst temperate forest regions.

Two calculations are made using this carbon sequestration average. One is made identifying the amount of carbon sequestered through a small-scale land protection organization, yielding a net carbon sequestration of approximately 224 metric tons of carbon per year. The other is based on the amount of land required to offset current anthropogenic emissions of carbon in the global carbon budget, showing approximately 235 million hectares of new forest growth would be required to offset current global anthropogenic emissions. One implication of these calculations is the traditional assumption of carbon neutrality increasing with age (Magnani et al., 2007) is incorrect, suggesting mature forest protection may be a favored policy choice for carbon sequestration strategies.
\end{abstract}

Keywords: Climate change, Carbon sequestration, Forests, Policy, Law

\section{Introduction}

For decades in the United States, land use policies have existed that favor planning to include the maintenance of open space. (Note 1) What may become an important question is how such land use policies support carbon sequestration as a means of absorbing net increases in atmospheric carbon concentrations. Recent research indicates old-growth forests may be serving as a continual net carbon sink over time (Luyssaert et al., 2008). This differs from previous work that assumed old-growth forests are "carbon neutral," where the change in carbon mass over time (also referred to as net ecological production) is zero (Odum, 1969). This research is supported by other studies showing net ecological production (via the continual accrual of carbon in forest systems) is robust, resisting various stressors like water deprivation and anthropogenic nitrogen fluxes (Magnani et al., 2007). Assuming natural background forest conditions, land use policies favoring forest re-growth will result in a continual net carbon storage capacity, even as the forest reaches full maturity.

One policy-relevant question to consider is the magnitude of the observed carbon sequestration potential for carbon mitigation purposes. For instance, assuming an average rate of carbon sequestration of $2.4+/-0.8 \mathrm{tC} \mathrm{ha}^{-1} \mathrm{yr}^{-1}(\mathrm{tC}=$ metric tons of carbon; ha = hectare; $\mathrm{yr}=$ year), how much land is required to be set aside for new forest growth in order to offset current anthropogenic forcing or carbon into the atmosphere? Calculations suggest an area approximately equivalent to the entire current forest area of the United States, or approximately 226 million hectares of new forest land, is required (explained in more detail below).

For application purposes, the calculated average carbon sequestration rate $\left(2.4+/-0.8 \mathrm{tC} \mathrm{ha}^{-1} \mathrm{yr}^{-1}\right)$ has been applied to a case study of land use policies favoring open space designations. Making certain assumptions about land use choices, a "net carbon offset" of continual forest growth in an area of Southeastern Massachusetts (referred to as "DNRT" lands below) has been determined. Using the ratios and carbon sequestration patterns established by Luyssaert et al. (2008), the net effect of small-scale land conservation measures on carbon sequestration efforts were determined. The suggestion is that continuation and expansion of open space policies, multiplied over larger spatial scales, can prove effective as a growing sink of carbon to offset current anthropogenic forcing of atmospheric carbon concentrations. 
Because of the substantial scales required to achieve full carbon offset, localized efforts multiplied over the entire globe may be an effective tool in implementing carbon mitigation through forest re-growth.

\section{Materials and Methods}

\subsection{Materials}

Original data was collected by Luyasserat et al. (2008), which can be found at: $\mathrm{http} / /$ www.nature.com/nature/journal/v455/n7210/extref/nature07276-s1.pdf. The heterotrophic respiration (Rh) to net primary production (NPP) ratio was validated at $0.65+/-0.02$, which represents a net carbon sink. The resulting 0.35 $(1.0-0.65)$ factor was used as a means of determining the net carbon sequestration of Southeastern Massachusetts temperate forest areas (assuming they would continue in an undisturbed and optimal density state). This resulted in an average net rate of carbon sequestration per unit area per unit time, or $2.4+/-0.8 \mathrm{tC} \mathrm{ha}^{-1} \mathrm{yr}^{-1}$.

Open space land use information was obtained using the sources identified in Table 1. The land use summary statistics database (updated November 2007) is maintained by the Massachusetts Department of Conservation and Recreation: Forestry Management Program. The protected and recreational open space database (updated February 2009) is maintained by the Massachusetts Executive Office of Energy and Environmental Affairs (EOEEA).

Relevant data was used to establish consistency in open space patterns and to ensure the validity of the original information obtained through DNRT research. This data was further used to identify DNRT lands that are capable of supporting full forest maturation, while also identifying areas incapable of forest maturation (wetland areas for example).

\subsection{Methods}

A database search was conducted to determine land areas within DNRT resources that can support forest ecosystem functions. A database search was conducted using Massachusetts land use information collected by the Department of Conservation and Recreation. The following land use designations were coded into regionalized zones for interpretation purposes. Each regionalized zoning code is translated into a landuse/zoning aggregate translation code, which is then given a unique classification ID scheme (see Figure 1). ID numbers of 1, 2, 3, 6, and 21 were used as identifiers of potential forested land for study purposes. Any additional lands held by DNRT, including those designated as "Residential" $(10,11,12,13)$ or Recreation $(7,8)$ were included where it was shown these lands were placed into sufficient private land use restrictions to provide sufficient time (at least 10 years based on data provided by Luyssaert et al. (2008)) for forest growth to incorporate continual net ecological production. Commercial land use designations (ID\# 15) were not incorporated into the study because they did not represent a significant source of DNRT lands, either through direct ownership or shared land use restrictions.

After coding was completed, DNRT lands under management were identified and analyzed to determine what percentage of DNRT land maintained sufficient forestry characteristics to be included in the study. Forestry characteristics was defined as land that was either currently identified as forest land, as well as land that is capable of becoming forest land over time (pasture land is one example). Other lands, such as submerged wetlands and salt-water wetlands, were not included for analysis purposes. The portion of DNRT land deemed capable of supporting forest growth became the basis for further evaluation.

A land use protection ratio was calculated based on changing rates of land use patterns over time in the town where DNRT lands reside. The assumption is that absent specific land use protection policies, DNRT protected lands would exhibit background rates of land transition observed in the local community. For instance, if the surrounding community was shown to be developing land at a rate of thirty percent (30\%) over the past decade, then it was assumed DNRT land, absent special protections, would also have this same rate of development. Data for rates of land use change in the town were obtained by using the Land Use Summary Statistics database maintained by the Massachusetts Department of Conservation and Recreation, as well as summary data provided by the Protected and Recreational Open Space database maintained by the Massachusetts Executive Office of Energy and Environmental Affairs (EOEEA).

The summary data identifies the current land use budget of the town for specific intervals: 1971, 1985, and 1999. (It just so happens DNRT began its land conservation operations in 1971, the same date as the earliest summary land use database currently available and accessible in public format.) Both the actual changes in land use (focusing primarily on the rate of increase in residential land measured against decreases in forested and agricultural land) and the rate of change was calculated for these intervals, with an overall rate of change calculated between 1971 and 1999. This rate of change was then used to measure the relative land mass protected by DNRT that was available for land modification to other uses (agricultural and residential), to determine a "net" forest conservation measure. This net forest conservation measure then served as the "baseline" from which further calculations of NEP were made. 
The land area identified as maintaining a net forest conservation measure was then subjected to a calculation using the NEP factor of 0.35 based on previous estimates (Luyssaert et al., 2008). The resulting number indicated the ultimate NEP potential, measured in tons of carbon per hectare per year $\left(\mathrm{tC} \mathrm{ha}^{-1} \mathrm{yr}^{-1}\right)$.

Land area needed to fully offset anthropogenic forcing of carbon was calculated using peer-reviewed estimates of current anthropogenic forcing rates (identified as 6.0 gigatons of carbon from direct anthropogenic forcing, and 0.9 gigatons based on a current net destruction of vegetation, for a total of 6.9 gigatons of carbon per year) (Schlesinger, 1997). This total forcing rate was then divided by the average carbon sequestration potential rate of new forest growth (2.4 $\left.\mathrm{tC} \mathrm{ha}^{-1} \mathrm{yr}^{-1}\right)$ to achieve a total land area required to mitigate current anthropogenic forcing of carbon.

To determine the effect of land use policies on NEP, a search of public and private laws in Massachusetts was conducted to determine the longevity potential of maintaining land in open space. A focus was placed on understanding the temporal extent of laws affecting land use restrictions favoring the continued designation of open space. The results of this search aids in further understanding the longevity of continued net carbon sequestration through forest development and maturation. While this search was not conducted comprehensively to determine the outer boundaries of legal tools for land use designations supporting forest growth and maturation, a cursory review was sufficient to ensure the current policies supporting DNRT preservation of lands is allowable for the immediate future (timeframes on the decadal scale). A more in-depth legal review would enhance this analysis to support some of the conclusions made below.

\section{Results}

Since its inception, the DNRT has actively engaged in land use restrictions on some 4,500 acres, or 1,800 hectares. The proportion of DNRT land that can be unequivocally identified as land capable of being developed but placed into reserves is approximately 1,500 acres, or 600 hectares. Using this number as a conservative estimate of open space (since they are designated as reserves), a potential rate of development based on average rates can be attached within the greater Town of Dartmouth from 1971 - 1999. Using the average rate of development over those twenty-eight (28) years, an increase in land transition into a developed state, on average, of $7.7 \%$ was seen. (Note 2) Using this average, one can conservatively assume DNRT efforts have saved approximately 47 hectares (600 hectares x .077). (Note 3) Using the data obtained, an average net carbon sequestration rate of $2.4+/-0.8 \mathrm{tC} \mathrm{ha}^{-1} \mathrm{yr}^{-1}$ was determined based on NEP for the 47 hectares. Taking the low, average, and extreme, the following rates of net carbon sequestration based on DNRT land preservation policy are:

$$
\begin{array}{llll}
\text { - } & \text { Low: } & \left(1.6 \mathrm{tC} \mathrm{ha}^{-1} \mathrm{yr}^{-1}\right) *(47 \mathrm{ha})= & 75 \mathrm{tCyr}^{-1} \\
\text { - } & \text { Average: } & \left(2.4 \mathrm{tC} \mathrm{ha}^{-1} \mathrm{yr}^{-1}\right) *(47 \mathrm{ha}) & =112 \mathrm{tCyr}^{-1} \\
\text { - } & \text { High: } & \left(3.2 \mathrm{tC} \mathrm{ha}^{-1} \mathrm{yr}^{-1}\right) *(47 \mathrm{ha})= & 150 \mathrm{tCyr}^{-1}
\end{array}
$$

Using a more liberal interpretation, to include some of the lands under managed restriction (Note 4), one can conservatively assume one-third (1/3) of the remaining 1,200 hectares under management are allowing for forest growth. This would equate to an additional 600 hectares subject to the same calculations and assumptions above, yielding a conservative estimate of human forest disturbance (resulting in the conversion of forest land) of an additional 47 hectares. Thus, the initial NEP values for net carbon sequestration can be doubled at the various low, average, and high rates of carbon sequestration. This would yield result in $150 \mathrm{tCyr}^{-1}$ for the low, $224 \mathrm{tCyr}^{-1}$ for the average, and $300 \mathrm{tCyr}^{-1}$ for the high.

Taking the average carbon sequestration per year, an extrapolation can be made to determine the extent of land area required to fully mitigate global anthropogenic forcing of carbon. For comparison purposes, the average of 224 metric tons of carbon sequestration per year is equivalent to $2.24 \times 10^{-7}$ gigatons per year (for 84 hectares of protection). Current net destruction of vegetation is calculated at approximately 0.9 gigatons of carbon per year (Schlesinger, 1997). Thus, it would take approximately 33,600,000 hectares of similar land protection to offset the current global net destruction of vegetation. The United States has approximately 226,000,000 hectares of forest land (FAO, 2001), so the amount of land needed to offset current global net destruction of vegetation would be approximately fifteen percent of the current total forest land of the United States. The amount of land to offset current anthropogenic burning of fossil fuels (approximately 6 gigatons of carbon per year) would be approximately six times the amount of land mass indicated to offset net destruction of vegetation, or 202,000,000 hectares. In this way, one can see the importance of U.S. forests, as total forest area in the U.S. (226,000,000 hectares) is roughly equivalent to the current global anthropogenic forcing of carbon emissions (from fossil fuel burning and net destruction of vegetation).

\section{Discussion}

The conservative estimates used in this study reveal a net carbon sequestration potential for land use planning policies that favor open space planning. The assumption is made that some proportion of uplands otherwise available for development will be deferentially treated for that purpose. As such, active planning to preserve and "re-grow" 
temperate forest areas can result in maximizing indirect use values such as carbon sequestration. The results of the conservative estimates suggest anywhere from 75 to 300 tons of carbon are sequestered each year as a result of DNRT preserving and re-growing temperate forest areas. For instance, a close examination of the information provided by Luyssaert et al. (2008) suggests temperate forests exhibit different NEP rates during different life stages, with the greatest rates of carbon sequestration occurring when the age of the forest is between the 5-10 year timeframe, maximizing at approximately $4.0 \mathrm{tC} \mathrm{ha}^{-1} \mathrm{yr}^{-1}$. This suggests efforts to re-establish temperate forests from other lands (agriculture for example) can have a significant impact within the first decade of establishment. Such timeframes are important considerations when balancing the benefits against the costs of open space policies. Further, since most of the protected forest (and those re-created through DNRT efforts) would have occurred within the last thirty-eight (38) years, the average net carbon storage is closer to the $2.4 \mathrm{tC} \mathrm{ha}^{-1} \mathrm{yr}^{-1}$ rate. Most importantly, a close review of the data suggests that while a reduction may occur in the yearly carbon sequestration after approximately year twenty (20), the rate will equalize and remain constant for about 100 subsequent years and longer. This is true even though the ultimate "carbon capacity" of the re-growth forest may be diminished from that of an original stand (Houghton et al., 1983; Harmon, Ferrell, \& Franklin, 1990).

The assumptions of undisturbed forest stands is conservative to the extent legal instruments exist to maintain the site in an undisturbed state for relatively long periods of time (on the order of 50 years). Massachusetts does contain both public and private laws that allow for the continued protection of open space on the timescale of decades. However, federal and state constitutional powers of eminent domain can supersede both public and private agreements relating to land conservation. A more in-depth analysis on how legal frameworks may affect such land use policies is advisable to fully consider the potential impacts of this study.

The assumption of optimal density is also conservative considering the current state of knowledge regarding forest density, age heterogeneity, growth factors, and carbon sequestration potential. Mangini et al. (2007) has done recent work on the effects of anthropogenic and natural disturbances to forest carbon sink activity. In order to better understand the effects of various stressors on forest systems, which are linked to the age-composition of the forest, age effects were filtered out by determining the average of carbon fluxes over the entire forest rotation, resulting in a net ecosystem production average, or $\mathrm{NEP}_{\mathrm{AV}}$. The results showed both anthropogenic-induced and natural stressors reduce, in parallel, both respiration and primary production. As a result, $\mathrm{NEP}_{\mathrm{AV}}$ is weakly correlated with such stressors. Instead, $\mathrm{NEP}_{\mathrm{AV}}$ is more highly correlated with the availability of limiting nutrients, such as nitrogen (Aber et al., 1998; Galloway et al., 2004). Thus, higher nutrient availability (through greater anthropogenic deposition of nitrogen) allows for continued forest growth and $\mathrm{NEP}_{\mathrm{AV}}$. The implications suggest the assumption of optimal density structure is conservative because age effects (the direct variable in determining optimal density) are of less importance than other factors (like availability of nutrients) when determining NEP. It is important to note the age effects analysis of Mangini et al. (2007) has been generally accepted, whereas their suggestion of a lack of nitrogen saturation through anthropogenic forcing has drawn some critical debate (De Schrijver et al., 2008; De Vries et al., 2008). For this analysis, it is clear the assumption that the protected forests will continue to grow to maturation, on the average, is conservative and bolstered by general trends of net forest re-growth identified in the literature (Caspersen et al., 2000). This is especially true where further conservative calculations have been made regarding the proportion of landmass being preserved, and the proportion that is viably adding to carbon sequestration rates through forest re-growth patterns has increased.

\section{Conclusion}

The results of this study suggest relatively small-scale preservation efforts of land suitable for forest growth can substantially impact global carbon budget patterns. While the scale of carbon sequestration rates in this study is orders of magnitude smaller than required to highly influence current global anthropogenic carbon budgets, an extrapolation of this small effort suggests the replication of small-scale measures, such as the DNRT example case, can mitigate anthropogenic fluxes of carbon into the atmosphere. While the total land area required to fully mitigate current anthropogenic forcing under the average rate of carbon sequestration is substantial, it is by no means impossible, especially if efforts for re-growth are diffused over the entire globe. Further, conservation measures limiting net deforestation can reduce the total amount of land required to fully mitigate anthropogenic forcing. It may be small-scale efforts at forest re-growth (bolstered by land conservation policies) can substantially aid in solving current anthropogenic carbon forcing.

While policies of carbon sequestration technologies are currently being discussed and tested (for example Herzog, 2001; Riahi, Rubin, Taylor, Schrattenholzer, \& Hounshell, 2004), it may be worthwhile to further evaluate land use policies favoring both maintenance and re-growth of temperate forest systems. Not only may forest re-growth policies serve (in the aggregate) as substantial and continual carbon sinks, but they also provide additional direct, indirect, and non-use values that are of interest to society (Plantinga \& Wu, 2003). Further work in this area would include expanding the 
current research to larger land holding operations, as well as a more in-depth analysis of legal principles and doctrines that ensure the longevity of land use policies favoring the continued protection of forest systems.

\section{References}

Aber, J., McDowell, W., Nadelhoffer, K., Magill, A., Berntson, G., Kamakea, M., Fernandez, I. (1998). Nitrogen saturation in temperate forest ecosystems. Bioscience, 48, 921-934.

Carey, E.V., Sala, A., Keane, R. \& Callaway, R.M. (2001). Are old forests underestimated as global carbon sinks? Global Change Biology, 7, 339-344.

Caspersen, J.P., Pacala, S.W., Jenkins, J.C., Hurtt, G.C., Moorcroft, P.R., \& Birdsey, R.A. (2000). Contributions of land-sue history to carbon accumulation in U.S. forests. Science, 290, 1148-1151.

De Schrijver, A., Verheyen, K, Mertens, J., Staelens, J., Wuyts, K., \& Muys, B. (2008). Nitrogen saturation and net ecosystem production. Nature, 451, E26.

De Vries, W., Solberg, S., Dobbertin, M., Sterba, H., Laubhahn, D., Reinds, G. J., ... Sutton, M.A. (2008). Ecologically implausible carbon response? Nature, 451, E26-E28.

Food and Agriculture Organization of the United Nations (FAO). (2001). Global Forest Resources Assessment 2000--main Report. FAO Forestry Paper No. 140. Rome: FAO. [Online] Available: http://www.fao.org/forestry/foris/webview/forestry2/index.jsp?siteId=101\&langId=1

Galloway, J.N., Dentener, F.J., Capone, D.G., Boyer, E.W., Howarth, R.W., Seitzinger, S.P., Voosmarty, C.J. (2004). Nitrogen cycles: past, present, and future. Biogeochemistry, 70, 153-226.

Harmon, M.E., Ferrell, W.K., \& Franklin, J.F. (1990). Effects of carbon storage of conversion of old-growth forests to young forests. Science, 247, 699-702.

Herzog, H. (2001). What future for carbon capture and sequestration: new technologies could reduce carbon dioxide emissions to the atmosphere while still allowing the use of fossil fuels. Environmental Science \& Technology, 35(7), 148A-153A.

Houghton, R.A., Hobbie, J.E., Melillo, J.M., Moore, B., Peterson, B.J., Shaver, G.R., \& Woodwell, G.M. (1983). Changes in the carbon content of terrestrial biota and soils between 1860 and 1980: a net release of $\mathrm{CO}_{2}$ to the atmosphere. Ecological Monographs, 53, 235-262.

Luyssaert, S., Schulze, E., Borner, A., Knohl, A., Hessenmoller, D., Law, B., Grace, J. (2008). Old-growth forests as global carbon sinks. Nature, 455, 213-215.

Magnani, F., Mencuccini, M., Norghetti, M, Berbigier, P., Berniger, F., Delzon, S., Grace, J. (2007). The human footprint in the carbon cycle of temperate and boreal forests. Nature, 447, 848-850.

Odum, E.P. (1969). The strategy of ecosystem development. Science 164, 262-270.

Plantinga, A. \&Wu, J. (2003). Co-benefits from carbon sequestration in forests: evaluating reductions in agricultural externalities from an afforestation policy in Wisconsin. Land Economics, 79, 74-85.

Pregitzer, K.S. \& Euskirchen, E.S. (2004). Carbon cycling and storage in world forests: biome patterns related to forest age. Global Change Biology, 10, 2052-2077.

Riahi, K., Rubin, E.S., Taylor, M.R., Schrattenholzer, L., \& Hounshell, D. (2004). Technological learning for carbon capture and sequestration technologies. Energy Economics, 26(4), 539-564.

Schlesinger, W.H. (1997). Biogeochemistry: an analysis of global change. San Diego: Elsevier Press.

Zhou, G., Liu, S., Li, Z, Zhang, D., Tang, X., Zhou, C, Mo, J. (2006). Old-growth forests can accumulate carbon in soils. Science, 314, 1417.

\section{Notes}

Note 1. For the purposes of this paper, open space can mean both areas limited to development due to legal restrictions, as well as areas that remain open simply due to a lack of will to develop the particular area in question.

Note 2. Calculation - 1971 Developed Land: 3,954 acres of 39,768 acres total land mass. 1999 Developed Land: 7,047 acres. Change from $1971-1999=3,092$ acres of 39,768 acres, or 7.7 percent of total land mass changed to developed land from 1971 to 1999.

Note 3. This calculation is based on the amount of DNRT reserve land that is technically capable of development (600 hectares), multiplied by the observed rate of development that has occurred within the vicinity in which these preserves are located (7.7 percent). 
Note 4. Managed restriction is meant to indicate lands held in private ownership, but are managed cooperatively between DNRT and the private landowner (using some form of private land use restriction agreement). This allows us to account for some of the 1,200 hectares of land in some form of partnership restriction based on DNRT efforts, but not part of the original 600 hectares currently under direct ownership by DNRT and in a preserved status.

Table 1. Sources for open space land information used in study

\begin{tabular}{|l|l|}
\hline \multicolumn{1}{|c|}{ Source } & \multicolumn{1}{c|}{ Information } \\
\hline Dartmouth Natural Resources Trust (DNRT) & Information with author. \\
\hline Mass GIS geodata system & www.mass.gov/mgis \\
\hline Mass GIS land use summary statistics & $\mathrm{http}: / /$ www.mass.gov/mgis/landuse_stats.htm \\
\hline Mass GIS protected and recreational open space & $\mathrm{http} / /$ www.mass.gov/mgis/osp.htm \\
\hline
\end{tabular}

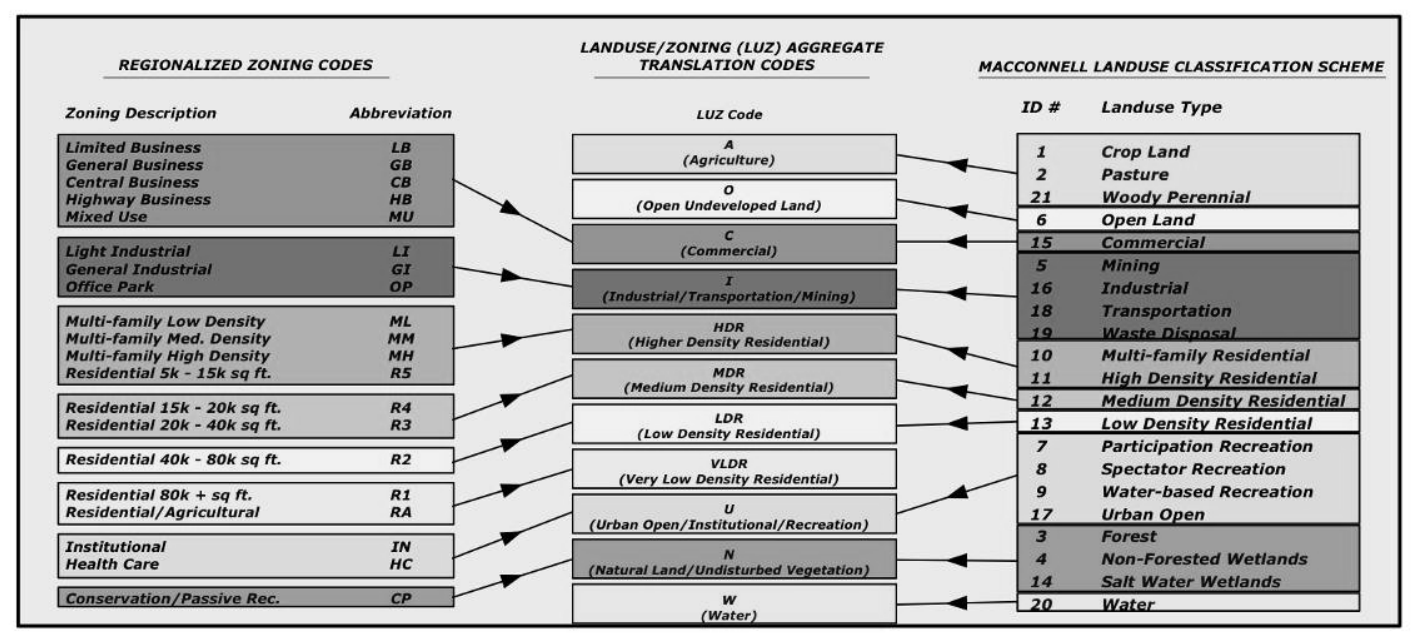

Figure 1. Land Use Aggregate Translation Code 